\title{
An Empirical Study of E-Service Quality and User Satisfaction of Public Service Centers in China
}

\author{
Chenghan Ming, College of Public Administration, Huazhong University of Science and Technology, Wuhan, China \\ Tao Chen, College of Public Administration, Huazhong University of Science and Technology, China, Wuhan, China \\ Qi Ai, Faculty of Business and Law, The University of Northampton, Northampton, UK \& College of Public \\ Administration, Huazhong University of Science and Technology, Wuhan, China
}

\begin{abstract}
This article describes how as part of the reform of the administrative system of China, most local governments have set up public service centers; meanwhile, ICT (Information and Communication Technology) has been commonly applied to make e-services more convenient, efficient and transparent. However, the existing studies in the Chinese context are mostly qualitative and the relationship between service quality and citizen satisfaction has not been tested. This article adopted the D\&M model to develop an e-service quality model and tested the impact of service quality on citizen satisfaction. A survey was conducted and 364 valid questionnaires were analyzed. The results showed that the data fit the model well. Most of the hypotheses formulated in this article was proven. Additionally, an important finding was that the impact of service quality on specific satisfaction is stronger than that of information quality and system quality, which indicates that face-to-face services cannot simply be substituted by electronic systems. Both the theoretical and practical implications of the findings were discussed.
\end{abstract}

\section{KEYWORDS}

China, E-Government, E-Service, Public Service Center, Service Quality

\section{INTRODUCTION}

As a result of the reform of the administrative system of China, many local governments have set up public service centers. Just as citizens can purchase various goods in a single supermarket, they can access various public services in a single hall, called either a public service center or an administrative service center. Most government sectors have set up access points in the hall and work together to offer one-stop services to the public. The purpose is to provide convenience to citizens, reduce the time and the stages needed for approvals, accept public supervision and prevent corruption. This practice has been considered as an important step towards the realization of a service-oriented government. 
As $\mathrm{Gu}(2015)$ said in a preface of one book, by the end of 2012, 35\% of province governments, $98 \%$ of city governments and $96 \%$ of county governments in China have set up public service centers.

In the development process of such public service centers, Information and Communication Technology (ICT) has been widely used to facilitate the setting up of the one-stop service, which have made significant progress. Most public centers have set up official websites to provide information and e-services to the public. Citizens can search online and inquire about the services, the processes, and the costs, download the relevant forms, and book appointments. Besides, E-government platforms have been developed to promote cross-department information sharing and collaboration. By adopting E-services and sharing information resources, the public service centers can improve government efficiency, reduce administrative costs, and improve public service quality.

Despite the increase in the literature on E-service quality (Parasuraman, Zeithaml, \& Malhotra, 2005; Carlson and O'Cass, 2010; Udo, Bagchi, \& Kirs, 2010; Yang, 2013; Mouakket, 2014; Stamenkov and Dika, 2015; Kao and Lin, 2016; Sá, Rocha, \& Cota, 2016), few of it has focused on public service centers and the empirical research is insufficient. Meanwhile, the relationship between E-service quality and user satisfaction in the Chinese context has not been the subject of sufficient attention. This research adopted the D\&M information system success model to develop an e-service quality model, and explored the impact of service quality on citizen satisfaction. A survey was conducted in the public service center in Xisaishan District, Huangshi City. The authors administered the survey questionnaire to citizens who had gone to the public service center to apply for services, and 364 valid responses were collected. This paper aimed at exploring and testing the mechanism among the dimensions of e-service quality, citizen satisfaction, and continuous motivation.

This paper is structured as follows. Firstly, it introduces the practices and studies of public service centers in China and reviews the existing research on E-government service quality and customer satisfaction. Secondly, it develops the research model and discusses the hypotheses formulated based on theories and practices. Thirdly, it introduces the research design and presents the results of the testing of both the model and the hypotheses. Finally, the paper draws its conclusions by discussing the implications, limitations, and future directions.

\section{LITERATURE REVIEW}

\section{Public Service Centers in China}

The history of public service center in China can be traced back to the 1980s. In the wave of the new public management movement that began in the late 1970s, many countries took innovative initiatives to improve public services; these included one-stop service centers in the UK, seamless government in the USA, kindness service hall in South Korea, etc. (Ruan, 2006). These practices had reduced the misalignment between the old government systems and the demand of new developments in economics and society. Some Chinese coastal open cities imitated these reforms and Chinese public service centers began to appear. According to a news article written by $\mathrm{Li}$ (2005), Guangzhou brought together three government sectors and nine consulting companies in one street to offer one-stop service to foreign companies in 1985. Guo (2016) found that, in 1995, Shenzhen had set up a foreign investment service center to centralize the approval process, while, in 1999, Jinhua had gathered 46 sectors, which held different approval powers, in one place to provide approval services to the public. It is easy to see that these early initiatives were just rudimentary public service centers and that most of them focused on economics and trades, offering few other services. Yu, Wu, \& Jiang (2016) found that public service centers began to appear from 2001, the same year in which China became a member of the WTO. These service centers were aimed at integrating fragmented services from different sectors and at providing better and more transparent services to the public by shortening the processes, cutting the costs, and enhancing the services. They were concrete manifestations of the construction of a legalization- and service-oriented government. As found by a study conducted by 
the Research Team of Chinese Society for Public Administration (2012), by the end of 2011, 2912 public service centers had been set up, $87.02 \%$ of which were on the county level.

In parallel to the flourishing of public service centers, scholars conducted many related studies. A considerable proportion of such literatures paid attention to the achievements, issues and strategies of public service centers (Ai and Yan, 2007; Jiang and Tao, 2007; Zhang and Qin, 2010). The adoption of public service center has obviously changed administrative styles and impacted approval behaviors. It has reduced corruption and has promoted E-government development. Although public service centers can provide better services and user experiences, a wide gap still exists between them and the demands for deeper reform. Some scholars applied related theories, such as New Pubic Management Theory, New Public Service Theory, Joined-Up Government Theory, and Gradient Theory to the construction and research of public service centers and discussed their issues and solutions (Xu, 2007; S. M. Zheng, C.Zheng, \& Liu, 2012;Zhuo and Chen, 2015; Chen,2015). Only a few of the papers consider the performance evaluation of public service centers. Liu \& Zheng (2015) found that administrative reform and personal relationships among officials and staff members could affect the cross-department collaboration in public service centers. Yu et al. (2016) built a framework and index system to evaluate performance based on Holistic Governance Theory but devoid of empirical testing.

It is clear that previous studies adequately introduced the development of public service centers in China and proposed many feasible suggestions for future directions. However, many of them were not adequately supported, as they lacked empirical research.

\section{E-Government Service Quality}

Since E-government relies on Information Technology (IT), research on E-government service quality can be traced back to that on e-service quality. The SERVQUAL model is very popular in this domain. This model was developed by Parasuraman, Zeithaml, \& Berry (1988) and modified by Parasuraman, Berry, \& Zeithaml (1991). In the model, the precondition of excellent service is user expectation, and service quality can be reflected by the confutation of expectations and perceptions. Parasuraman et al. (2005) thought that this model can be modified as a function of different backgrounds. Kettinger \& Lee (1994) adopted this model in their research and proved its suitability in the user satisfaction domain. By means of an empirical study on different kinds of organizations in four countries, Pitt, Watson, \& Kavan (1995) tested the reliability and validity of the measurement scale and proved that SERVQUAL could estimate the service quality of an information system. During the $5^{\text {th }}$ International Conference, EGOV 2006, Papadomichelaki, Magoutas, Halaris, Apostolou, \& Mentzas (2006), presented a review on the research on E-government service quality and found that service, content, systems, and organization were the four main components affecting E-government service quality. In his research, Susniene (2012) employed the SERVQUAL model and made it possible to measure customer satisfaction with it. The results provided "valuable information and guidelines for transport service companies on necessary improvements in their daily operations" (p.102).

On the other hand, according to the research carried out by Wang, Y. Q. Xie, \& X. Xie (2014), DeLone and McLean created D\&M Information System (IS) Success Model in 1992, based on Shannon and Weaver's research on Communication System Theory, Mason's Information Influence Theory, and the empirical literatures on Management Information System (MIS) of the 1980s. Seddon and Kiew (1996) slightly modified this model and pointed out the relevance of "Task Importance". The model was split into a partial IS behavior model and an IS success model, and the former was verified by empirical data. Pitt et al. (1995) proposed a five-dimensional evaluation criterion for IS service quality and suggested that it should be adopted by the IS success model. Adopting part of the results of discussion and research on the D\&M IS model, Delone and McLean (2003) made a ten-year update for it. In the new edition, information, system, and service are the three dimensions for evaluating IS service quality. Information quality (INFQ) estimates the quality of a website, system quality (SYSQ) estimates the availability, reliability, adaptability and usefulness of an electronic commerce system, and service quality (SERQ) evaluates the relationship between 
a system and its users. Following this, Wang and Liao (2008) verified the feasibility of the new model by conducting an empirical study in Taiwan. In Hong Kong, Hu, Brown, Thong, Chan, \& Tam (2009) found that the key determinants of service quality were service characteristics and technology and that, instead of perceived usefulness, service quality was the strongest predictor of continuance intention. By applying marketing exchange theory, Ding (2010) redefined service quality, information quality, and system quality and conducted an empirical research to test the validity and relevance of the three dimensions. At the same time, Wangpipatwong, Chutimaskul, \& Papasratorn (2010) proved that INFQ, SYSQ and SERQ can significantly increase the continued use of E-Government websites.

Visibly, the existing literature has made significant contributions to the research domain and has given us a huge space to explore. However, it is clear that there is still no unified research model for e-Government service quality. Scholars have developed a series of concept models, but the related empirical research (especially in the context of China) is insufficient and the measurement index should be improved.

\section{Customer Satisfaction}

According to the definition given by Giese \& Cote (2000), consumer satisfaction is "a summary affective response of varying intensity with a time-specific point of determination and limited duration, directed toward focal aspects of product acquisition and/or consumption”. In this study, the authors regarded the citizen satisfaction with E-service as a form of consumer satisfaction and called it customer satisfaction for unification purposes.

Customer satisfaction index (CSI) model has far-reaching impact on the international research and practice on customer satisfaction. For example, on the Website of ACSI (2016), website, it can be seen that the American Customer Satisfaction Index (ACSI) has become the nation's only cross-industry measure of customer satisfaction, with the NCSI-UK as a companion index for the British national economy. Adapted from ACSI, an online customer satisfaction index for the context of Taiwan was developed by Hsu (2008). As Yang (2013) affirmed, the CSI model places customer satisfaction at its core and puts the antecedents and outcome variables of customer satisfaction into a systematic network chain. Carlson and O'Cass (2010) explored the relationships among E-service quality, customer satisfaction, attitudes, and behavioral intentions in content-driven web sites, and verified the positive relationship among the variables. Udo et al. (2010)examined the relationship among E-service quality perception, satisfaction, and intention in an E-business environment. The result showed that "the indirect or mediating influence of satisfaction on web, service quality and behavioral intentions is indeed stronger than the direct influence of web service, quality on behavioral intentions" (p. 481). Mouakket (2014) found a significant chain of E-service quality, utilitarian values, hedonic values, customer satisfaction, and continuance intentions in the context of United Arab Emirates. Subramanian, Gunasekaran, Yu, Cheng, \& Ning (2014) identified that the dominant customer satisfaction factors were: reliability in service quality; and purchasing experience in E-service quality.

In summary, the existing literature on customer satisfaction has undergone a lively development. Some of it has already explored the relationship between E-service quality and customer satisfaction with interesting findings. Nevertheless, quantitative research on E-government service quality is relatively insufficient. Furthermore, the services provided in public service centers are usually combinations of online and offline services. Public service centers are not going to be completely replaced by online services, at least in the short term. However, most of the existing literature surveyed website users by means of questionnaires. It is difficult to ensure the representative of the respondent sample and it may not be possible to generalize the findings to the real population of public service center customers. 


\section{HYPOTHESES AND THEORETICAL MODEL}

\section{Hypotheses}

By adopting the modified D\&M information system success model, service quality (SQ) was evaluated in the three dimensions of information, system, and service. As proposed by Zhang (2009), the authors divided satisfaction into two categories: specific satisfaction and accumulative satisfaction. Also, as mentioned above, continuous motivation was adopted as a dependent variable in the research.

Between inquiring and receiving service, citizens have to understand and obtain all relevant information. In this study, the information quality refers to perceived evaluations in the wake of inquiring and obtaining information. Only if they have sufficient and accurate information can citizens effectively submit relevant materials and get access to services. Information quality is bound to have an impact on final satisfaction. Therefore, the following hypotheses were proposed.

H1: Information quality has a significant positive impact on specific satisfaction.

H2: Information quality has a significant positive impact on accumulative satisfaction.

System quality refers to the evaluation of an e-government system, including a series of electronic and network systems and platforms-such as on-line reservations, taking access number on-site, event handling, and a series of related activities. Systematic service runs throughout the entire process-such as reservation, receipt, handling field service, etc. All procedures rely on the regulation of E-gov systems. Citizens will give certain rating to the regulation and process, and to the friendliness of the system itself. Therefore, the following hypotheses were proposed.

H3: System quality has a significant positive impact on specific satisfaction.

H4: System quality has a significant positive impact on accumulative satisfaction.

As known, public service centers are the material extensions of the online reservation and receipt of an administrative service. Many administrative service items have to be completed offline in public service centers. Many services are not provided by standardized electronic system and template information, but by a real office and its staff. The service quality mentioned here refers to the evaluation of the field services provided by public service centers. It pays more attention to "individual" factors and concentrates on "individual" evaluations. In terms of individual cognitive psychology, the services provided by public service center are bound to affect the final satisfaction evaluation. Therefore, the following hypotheses were proposed.

H5: Service quality has a significant positive impact on specific satisfaction.

H6: Service quality has a significant positive impact on accumulative satisfaction.

Specific satisfaction refers to the recently perceived satisfaction in receiving E-service. It is reflected by the gap that exists between the actual and expected services. Accumulative satisfaction refers to overall satisfaction since first access to E-service. It is generally agreed that, when making evaluations, people will be affected not only by the halo effect, but also by the recent effect. Therefore, the following hypothesis was proposed.

H7: Specific satisfaction has a significant positive impact on accumulative satisfaction.

As mentioned above, the existing literature has already proved that customer satisfaction has an important impact on continuous motivation. However, in the domain of government services, service subject generally cannot be pre-determined. Therefore, it was just assumed that the citizens 
could choose any service they wanted in the future. Then, the respondents were asked whether, when faced with a similar need, they would choose to satisfy it in the same fashion. This could reflect the effects of satisfaction on continuous motivation. Therefore, the following hypotheses were proposed.

H8: Specific satisfaction has a significant positive impact on continuous motivation.

H9: Accumulative satisfaction has a significant positive impact on continuous motivation.

\section{Theory Model}

Figure 1 presents all the hypotheses and the whole model. Three control variables (i.e., service experience, service category, and service mode) were taken into consideration. These may influence continuous motivation. Service experience refers to whether a citizen has already utilized the public service center in the past. Service category refers to whether the service requested is for personal or business use. Service mode refers to whether the service can be self-obtained or requires assistance.

\section{RESEARCH DESIGN}

\section{Variable Measurement}

The measured items for all the latent variables (LV) in this study were adopted and modified from previous studies, using a 5-point Likert Response Format (LRF) scale. The scales for information quality, system quality and service quality were adopted from Wang and Liao (2008) and Kang and Lee (2010). The satisfaction items were based on the scales proposed by Zhang (2009) and Lin, Chen, $\&$ Fang (2011). The continuous motivation items were adopted from Wangpipatwong, Chutimaskul, \& Papasratorn (2008) and Yeh and Teng (2012). For the control variables, categorical scales were used to measure service experience (yes and no), service category (personal service and business service), and service mode (self-service and human-service). All the measured variables (MV) and latent variables are listed in Table 1.

\section{Data Collection}

The authors choose the public service center in Xisaishan District, Huangshi City, as the case for the research. Xisaishan is a county-level region in the Hubei province of Central China. This particular

Figure 1. Research Model

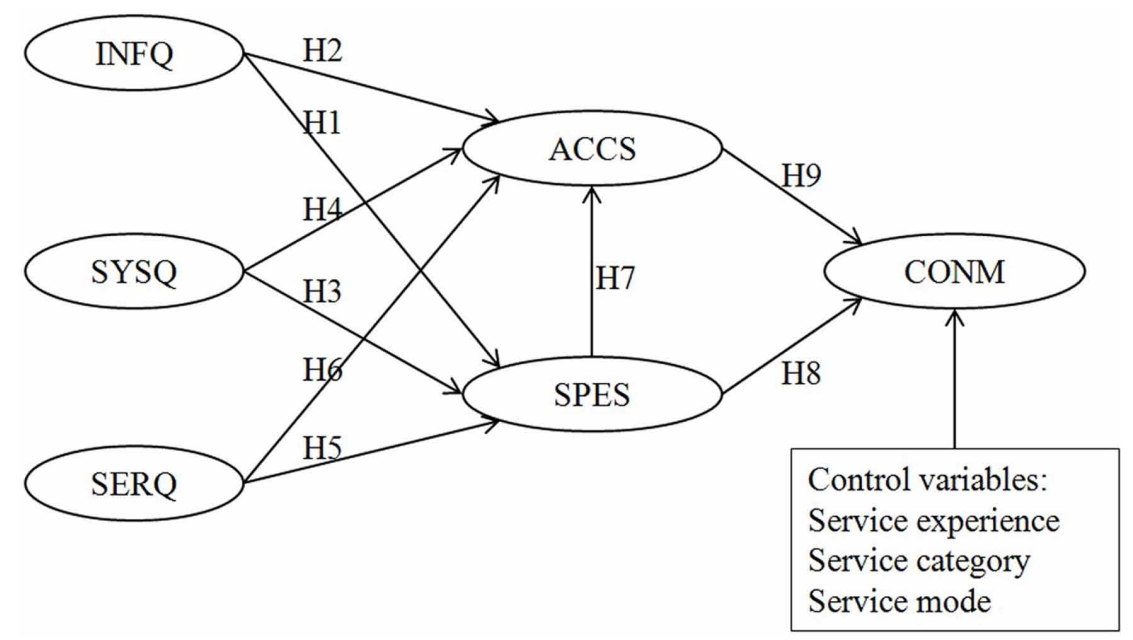


Table 1. Latent variables and measured variables

\begin{tabular}{|c|c|}
\hline $\mathbf{L V}$ & MV \\
\hline \multirow{4}{*}{ Information quality(INFQ) } & INFQ1. The service center offers precise information. \\
\hline & INFQ2. The service center offers sufficient information. \\
\hline & INFQ3. The service center offers up to date information. \\
\hline & INFQ4. The service center offers information of a high quality. \\
\hline \multirow{3}{*}{ System quality(SYSQ) } & SYSQ1. The equipment and system interfaces in the service center are user-friendly. \\
\hline & SYSQ2. The equipment and systems in the service center are very easy to use. \\
\hline & SYSQ3. Overall, the whole system in the service center is of a very high quality. \\
\hline \multirow{3}{*}{ Service quality(SERQ) } & SERQ1. Staff members show willingness to help me solve my problems. \\
\hline & SERQ2. I feel safe and sound in handling my affairs in the service center. \\
\hline & SERQ3. The staff members show great interest in my situation. \\
\hline \multirow{3}{*}{ Specific satisfaction(SPES) } & SPES1. The last time, I was very satisfied with the service center. \\
\hline & SPES2. The last time, the result went beyond my expectation. \\
\hline & SPES3. The last time, I had a very good experience. \\
\hline \multirow{3}{*}{$\begin{array}{l}\text { Accumulative } \\
\text { satisfaction(ACCS) }\end{array}$} & ACCS1. My experiences in the service center are always very good. \\
\hline & ACCS2. The service center always meets my expectations. \\
\hline & ACCS3. Overall, I am always satisfied with the service center. \\
\hline \multirow{2}{*}{$\begin{array}{l}\text { Continuous } \\
\text { motivation(CONM) }\end{array}$} & CONM1. I would visit the service center if I had similar needs in the future. \\
\hline & CONM2. If I could choose, I would go to nowhere else but to the service center. \\
\hline
\end{tabular}

public service center was chosen because of the following reasons. Firstly, most of China's public service centers are at the county-level and citizens generally get public services from local government. Secondly, after running for several years, it is in need of upgrading and necessitates some solutions to be found through research. Lastly, as a county-level region in Hubei, Xisaishan is in the forefront of the construction of public service centers.

The authors developed a questionnaire on public service center service quality and customer satisfaction, and came to its final form through five stages: first draft, advisory discussion, preliminary questionnaire, pilot testing, and discussion \& modification.

Citizens applying for E-services in the public service center were surveyed by having the questionnaires issued randomly to them. 429 valid questionnaires of 500 issued were collected. After excluding those with missing answers, 364 were used. Table 2 shows the sample demographics.

\section{RESULTS}

\section{Model Evaluating}

Generally speaking, Covariance-based Structural Equation Modeling (CB-SEM) is a widely used statistic analysis method. However, Wong (2013) stated that it requires high data quality and large sample sizes, which, in practice, often cannot be provided. So, the partial least squares (PLS) technique is often adopted as an alternative to CB-SEM because it makes no assumptions in relation to data distribution and can also complete the task of SEM analysis very well. The authors thus chose PLS for this paper's data calculation and analysis because the sample was not very big and predictive accuracy was important; also, the model should be further examined. 
Table 2. Sample demographics

\begin{tabular}{|c|c|c|c|}
\hline Characteristic & Range & Frequency & Percentage \\
\hline \multirow{2}{*}{ Gender } & Male & 170 & $46.70 \%$ \\
\hline & Female & 194 & $53.30 \%$ \\
\hline \multirow{6}{*}{ Age } & $\leq 20$ & 18 & $4.95 \%$ \\
\hline & $21-30$ & 91 & $25.00 \%$ \\
\hline & $31-40$ & 102 & $28.02 \%$ \\
\hline & $41-50$ & 87 & $23.90 \%$ \\
\hline & $51-60$ & 58 & $15.93 \%$ \\
\hline & $\geq 61$ & 8 & $2.20 \%$ \\
\hline \multirow{5}{*}{ Education } & Master and above (include MBA) & 7 & $1.92 \%$ \\
\hline & Bachelor & 85 & $23.35 \%$ \\
\hline & Junior college & 83 & $22.80 \%$ \\
\hline & High School & 121 & $33.24 \%$ \\
\hline & Secondary School and below & 68 & $18.68 \%$ \\
\hline \multirow{8}{*}{ Occupation } & Government or institution staff & 41 & $11.26 \%$ \\
\hline & Business staff & 54 & $14.84 \%$ \\
\hline & Self-employed & 56 & $15.38 \%$ \\
\hline & Retired & 40 & $10.99 \%$ \\
\hline & Unemployed & 24 & $6.59 \%$ \\
\hline & Teacher & 10 & $2.75 \%$ \\
\hline & Student & 19 & $5.22 \%$ \\
\hline & Other & 120 & $32.97 \%$ \\
\hline \multirow{6}{*}{ Monthly income (RMB) } & $<1000$ & 41 & $11.26 \%$ \\
\hline & $1000-1999$ & 134 & $36.81 \%$ \\
\hline & $2000-2999$ & 145 & $39.84 \%$ \\
\hline & $3000-3999$ & 34 & $9.34 \%$ \\
\hline & $4000-4999$ & 6 & $1.65 \%$ \\
\hline & $\geq 5000$ & 4 & $1.10 \%$ \\
\hline
\end{tabular}

To begin with, indicator reliability was tested. According to the basic test indicators for PLS defined by Wong (2013), the outer loadings' square should be more than 0.4 and preferably be 0.7 or more. Thus the outer loadings should be more than 0.632 and preferably be 0.837 or more. The results showed that all the outer loadings of the items on latent variables were at an acceptable level, ranging from 0.797 to 0.927 , indicating that the measurement model has a high reliability. The details are listed in Table 3.

Secondly, internal consistency reliability was tested. The results showed that all the Cronbach $\alpha$ value were larger than 0.7 , and the composite reliability (CR) values were around 0.9 . These two indicators indicated that the internal consistency reliability was good. The correlation matrix of latent variables is indicated in Table 4. 
Table 3. Outer loadings of LV

\begin{tabular}{|c|c|c|c|c|c|c|c|c|}
\hline MV & Mean & SD & INFQ & SYSQ & SERQ & SPES & ACCS & CONM \\
\hline INFQ 1 & 3.904 & 0.909 & 0.839 & 0.609 & 0.604 & 0.581 & 0.581 & 0.597 \\
\hline INFQ 2 & 3.838 & 0.984 & 0.867 & 0.636 & 0.577 & 0.602 & 0.556 & 0.563 \\
\hline INFQ 3 & 3.824 & 1.000 & 0.838 & 0.620 & 0.518 & 0.542 & 0.500 & 0.520 \\
\hline INFQ 4 & 3.951 & 0.955 & 0.829 & 0.687 & 0.565 & 0.583 & 0.575 & 0.520 \\
\hline SYSQ 1 & 3.909 & 0.912 & 0.658 & 0.852 & 0.559 & 0.569 & 0.521 & 0.540 \\
\hline SYSQ 2 & 3.898 & 1.003 & 0.673 & 0.878 & 0.597 & 0.566 & 0.580 & 0.519 \\
\hline SYSQ 3 & 3.984 & 0.927 & 0.633 & 0.864 & 0.674 & 0.618 & 0.573 & 0.589 \\
\hline SERQ 1 & 4.135 & 0.939 & 0.543 & 0.590 & 0.839 & 0.592 & 0.550 & 0.582 \\
\hline SERQ 2 & 4.143 & 0.873 & 0.528 & 0.585 & 0.860 & 0.602 & 0.537 & 0.567 \\
\hline SERQ 3 & 4.005 & 0.962 & 0.619 & 0.595 & 0.797 & 0.505 & 0.474 & 0.499 \\
\hline SPES 1 & 4.126 & 0.885 & 0.569 & 0.590 & 0.644 & 0.883 & 0.673 & 0.624 \\
\hline SPES 2 & 4.044 & 0.967 & 0.621 & 0.594 & 0.568 & 0.870 & 0.586 & 0.596 \\
\hline SPES 3 & 4.099 & 0.879 & 0.601 & 0.581 & 0.566 & 0.856 & 0.607 & 0.600 \\
\hline ACCS 1 & 4.033 & 0.979 & 0.575 & 0.563 & 0.543 & 0.591 & 0.881 & 0.611 \\
\hline ACCS 2 & 3.973 & 0.927 & 0.584 & 0.557 & 0.563 & 0.650 & 0.901 & 0.639 \\
\hline ACCS 3 & 4.107 & 0.898 & 0.577 & 0.586 & 0.549 & 0.648 & 0.857 & 0.613 \\
\hline CONM 1 & 4.080 & 0.928 & 0.601 & 0.563 & 0.592 & 0.631 & 0.661 & 0.925 \\
\hline CONM 2 & 4.052 & 0.936 & 0.608 & 0.614 & 0.634 & 0.661 & 0.646 & 0.927 \\
\hline
\end{tabular}

Note: The Means and SDs were calculated by SPSS 19.0 .

Table 4. Correlation matrix of LV

\begin{tabular}{|l|l|l|l|l|l|l|l|l|l|}
\hline & $\begin{array}{c}\text { Cronbach } \\
\boldsymbol{\alpha}\end{array}$ & \multicolumn{1}{|c|}{ CR } & \multicolumn{1}{|c|}{ AVE } & INFQ & \multicolumn{1}{|c|}{ SYSQ } & SERQ & SPES & ACCS & CONM \\
\hline INFQ & 0.864 & 0.908 & 0.711 & $\mathbf{0 . 8 4 3}$ & & & & & \\
\hline SYSQ & 0.831 & 0.899 & 0.747 & 0.757 & $\mathbf{0 . 8 6 5}$ & & & & \\
\hline SERQ & 0.778 & 0.871 & 0.693 & 0.673 & 0.707 & $\mathbf{0 . 8 3 2}$ & & & \\
\hline SPES & 0.839 & 0.903 & 0.756 & 0.685 & 0.676 & 0.683 & $\mathbf{0 . 8 7 0}$ & & \\
\hline ACCS & 0.854 & 0.911 & 0.774 & 0.657 & 0.646 & 0.627 & 0.716 & $\mathbf{0 . 8 8 0}$ & \\
\hline CONM & 0.834 & 0.923 & 0.858 & 0.653 & 0.636 & 0.662 & 0.698 & 0.706 & $\mathbf{0 . 9 2 6}$ \\
\hline
\end{tabular}

Note: The number on the diagonal line is the arithmetic square root of AVE of the corresponding latent variable.

Finally, convergent validity and discriminant validity were tested. As showed in Table 4, the average variance extracted (AVE) of each latent variable is much larger than the minimum acceptable threshold of 0.5 , so convergent validity is confirmed. Meanwhile, the arithmetic square root of each AVE is large than the other correlation values among the latent variables. For example, the latent variable SPES's AVE is 0.756; hence, its square root is 0.870 . This number is larger than the correlation values in the SPES column (0.716 and 0.698) and also larger than those in the SPES row $(0.685,0.676$, and 0.683$)$. All other similar results can be seen in Table 4 . Thus, it can be said that discriminant validity is satisfied. 
As seen in Table 3, the outer loadings of latent variables are high. So the existence of multicollinearity needs to be examined. After calculating the variance inflation factors (VIF) with SPSS 19.0, the authors found that the VIF values of all the latent variables ranged from 2.052 to 2.815 , lower than the maximum acceptable threshold of 5.0. Thus, multi-collinearity was insignificant in this study.

\section{Hypotheses Testing}

Hierarchical regression analysis was adopted to test the hypotheses. Two models were developed in PLS. In the first model, only the control variables were taken into consideration. Then the second model adopted the independent variables to evaluate $\mathrm{H} 1 \sim \mathrm{H} 9$. The hierarchical regression results are indicated in Table 5.

The table shows the results of the hierarchical regression analysis, the explained latent variable variances $\left(\mathrm{R}^{2}\right)$, standardized path coefficients, $\mathrm{f}^{2}$ (effect size) among exogenous latent variables and endogenous latent variables and the significance of path coefficients. Model 1 in Table 5 indicates that, of all the three control variables, only service experience significantly and negatively affects continuous motivation. So, it can be said that regardless of the kind of service a citizen applies for or of how the service will be provided, it will have almost nothing to do with continuous motivation. However, citizens who have already used the public service center have lower motivation to do so again. Maybe they think that one administrative approval should not be divided into several parts. Or they think that some of the services should be available to be completed online and there should be no need to visit the public service center several times.

Model 2 in Table 5 indicates that, except for the path from SERQ to ACCS-which is insignificantall the other coefficients are significant. Thus, only H6 was unsupported. This result might be due to two reasons. One is the SERQ bias in evaluating the staff members of the public service center, who, however, may be transferred. Changes in staff and, maybe, different levels of service do not contribute much to ACCS. The other reason is that SERQ is much more subjective-compared to INFQ and SYSQ- and ACCS represents an overall impression, so the link between them maybe weak. At the same time, Table 5 shows that the effect size values are highly consistent with the path coefficients and their significance. The path coefficients of the last model can be seen in Figure 2.

Table 5. Hierarchical regression results

\begin{tabular}{|c|c|c|c|c|c|}
\hline & Model 1 & Model 2 & & Model 1 & Model 2 \\
\hline Block 1: Control variable & & & $\mathrm{ACCS} \rightarrow \mathrm{CONM}(\mathrm{H} 9)$ & & $0.411 * * *$ \\
\hline Service experience & $-0.198 * * *$ & -0.057 & $\mathrm{R}^{2}$ (SPES) & & 0.576 \\
\hline Service category & -0.052 & 0.049 & $\mathrm{R}^{2}$ (ACCS) & & 0.584 \\
\hline Service mode & 0.078 & 0.059 & $\mathrm{R}^{2}(\mathrm{CONM})$ & 0.048 & 0.584 \\
\hline Block 2: Main effect & & & $\mathrm{f}^{2}($ Effect size $)(\mathrm{INFQ} \rightarrow \mathrm{SPES})$ & & 0.083 \\
\hline $\mathrm{INFQ} \rightarrow \mathrm{SPES}(\mathrm{H} 1)$ & & $0.301 * * *$ & $\mathrm{f}^{2}($ Effect size $)(\mathrm{INFQ} \rightarrow \mathrm{ACCS})$ & & 0.031 \\
\hline $\mathrm{INFQ} \rightarrow \mathrm{ACCS}(\mathrm{H} 2)$ & & $0.189 * *$ & $\mathrm{f}^{2}($ Effect size $)($ SYSQ $\rightarrow$ SPES $)$ & & 0.038 \\
\hline $\mathrm{SYSQ} \rightarrow \mathrm{SPES}(\mathrm{H} 3)$ & & $0.217 * * *$ & $\mathrm{f}^{2}($ Effect size $)(\mathrm{SYSQ} \rightarrow \mathrm{ACCS})$ & & 0.017 \\
\hline $\mathrm{SYSQ} \rightarrow \mathrm{ACCS}(\mathrm{H} 4)$ & & $0.142 *$ & $\mathrm{f}^{2}($ Effect size $)($ SERQ $\rightarrow$ SPES $)$ & & 0.113 \\
\hline $\mathrm{SERQ} \rightarrow \mathrm{SPES}(\mathrm{H} 5)$ & & $0.326 * * *$ & $\mathrm{f}^{2}($ Effect size $)(\mathrm{SERQ} \rightarrow \mathrm{ACCS})$ & & 0.014 \\
\hline $\mathrm{SERQ} \rightarrow \mathrm{ACCS}(\mathrm{H} 6)$ & & 0.121 & f2(Effect size $)($ SPES $\rightarrow$ ACCS $)$ & & 0.168 \\
\hline $\mathrm{SPES} \rightarrow \mathrm{ACCS}(\mathrm{H} 7)$ & & $0.408 * * *$ & $\mathrm{f}^{2}($ Effect size $)($ SPES $\rightarrow$ CONM $)$ & & 0.188 \\
\hline $\mathrm{SPES} \rightarrow \mathrm{CONM}(\mathrm{H} 8)$ & & $0.400 * * *$ & $\mathrm{f}^{2}($ Effect size $)(\mathrm{ACCS} \rightarrow \mathrm{CONM})$ & & 0.195 \\
\hline
\end{tabular}

Note: ${ }^{*} p<0.05 ;{ }^{* *} p<0.01 ;{ }^{* * *} p<0.001$ 


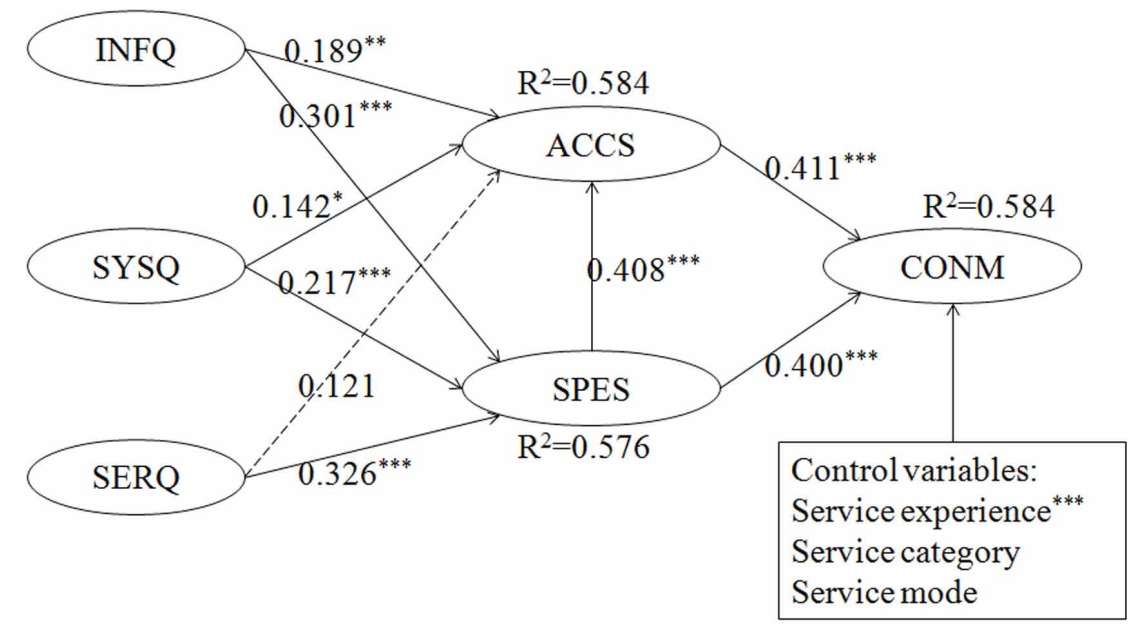

Note: $* \mathrm{p}<0.05 ; * * \mathrm{p}<0.01 ; * * * \mathrm{p}<0.001$

\section{DISCUSSIONS AND IMPLICATIONS}

\section{Theoretical Implications}

As an empirical research, this paper effectively explored and verified the influence mechanism linking several related variables. The authors successfully applied the D\&M IS success model and the theory of customer satisfaction to the field of E-government service. The research perspective has been broadened and the applicability of the model has been verified. Meanwhile, the way in which the researchers obtained the first-hand data from the public service center was very significant to the empirical study of E-service quality. This paper provided a useful reference to the theoretical research on and practical reform of E-government.

This research showed that the data adequately fit the measurement model and structural model. The results indicated that the dimensions of service quality in the D\&M model could perform well in E-government research. With the exception of H6, all the other hypotheses passed the test with different level of significance. INFQ, SYSQ and SERQ significantly and positively affected SPES. INFQ and SYSQ significantly and positively affected ACCS. Both SPES and ACCS positively affected CONM with a high level of significance. Compared to that of ACCS, the influence of INFQ, SYSQ, and SERQ on SPES is much stronger. One possible interpretation is that the respondents were investigated shortly after having accessed the services. The fresh impression of SQ helped them to evaluate SPES with more intuitive feelings and more clear criteria. When evaluating ACCS, the citizens only gave an overall score. This score might be just subjective and not influenced by SQ. At the same time, it showed that SPES positively affected ACCS with a significance of 0.001 and with a path coefficient of 0.408 , which means that this path is very stable. Thus, the mediating role of SPES between SQ and ACCS can be studied in the future.

Interestingly, albeit having the same significance level of 0.001 , the path coefficient of SERQ to SPES is much higher than those of SYSQ and INFQ. Two reasons may explain this. First, the E-government system has been widely adopted and is popular in government services. The ways of obtaining information and using the E-Gov system may be already widely known by the citizens. Those things that are in their knowledge purview may not contribute much to the SPES. Second, the SQ was assessed in the last stages of administrative approval. The service was provided by human staff members, and not by the software system. The professional diathesis and service level of the 
staff might played a more important role in the evaluation process. The results also showed that ACCS exerted a more significant effect on CONM than on SPES. It is easy to accept that accumulative satisfaction contributes more than specific satisfaction to continuous motivation.

\section{Practical Implications}

As an important channel for the delivery of government services, county-level public service centers have played a significant role in improving service quality and public satisfaction. Several practical implications can be generalized from this research.

First, SPES should receive more attention. Though ACCS can be significantly and positively affected by both INFQ and SYSQ, the coefficients are small and the level of significance is low. However, the three dimensions of SQ all very significantly influence SPES. And as mentioned above, SPES seems to play a mediating role between SQ and ACCS, and also significantly and positively affects CONM. Thus, it can be concluded that SPES plays a decisive role in the model. So, measures should be taken to improve SPES.

Second, SERQ should be regarded as an important factor for the improvement of SPES. Compared to INFQ and SYSQ, SERQ has a greater effect on SPES. The experience in public service center and the service provided by the staff members have a directed influence on the evaluations. Thus, in the premise of ensuring information quality and system quality, public service center staff service consciousness and quality should be improved.

Third, the administrative system reform should go further and deeper. Information, E-government system, and staff service quality improvements can only be seen as technical level reforms. Compared with SPES, ACCS has a greater effect on CONM. Thus, just concentrating on technical aspects is not enough. Much more attention should be paid to improving the overall impression of the public service center. Only by decentralizing more power and reducing the administrative steps can the reform go further and engender more satisfaction and user stickiness so as to guarantee continuous motivation.

\section{CONCLUSION, LIMITATIONS AND FUTURE RESEARCH}

This study verified the applicability of the SQ dimensions of the D\&M model to the field of public service center E-service quality in China. The authors conducted a normative empirical research that may act as a good basis for further studies. The results have important guiding significance for the practice of administrative reform. First, since the public service center's mission is to provide better service to the public, and the most effective evaluations of it should be made by the public, publicoriented service and public participation should earn more attention. Second, the links between online and offline services should be improved and the procedures should be modified according to the demands of the society and scientific service standards. Third, besides gathering different sectors to work together, the integration of related services which are distributed in different departments and the integration of technology, culture and social power should be taken into practice. Only in this way can public service centers provide more competitive services. Fourth, quality chain management should be applied in order to get much more comprehensive evaluations and feedback of the services. Fifth, as mentioned above, actions should be taken to improve the staffs' professional service ability and face-to-face service level.

This research has some limitations. First, this paper excluded all the questionnaires with missing data. This may have led to neglecting some information. Second, the data used in this paper were collected from a single public service center. Thus, the universality and applicability of this research may be limited. Third, the investigation was conducted in China and the situations may not be the same in other countries. Further survey should be conducted to test whether the model is suited to different countries.

This study is just an exploration and much more related research should be done in the future. First, the influence mechanism of the related factors should be further explored. The influence of 
public participation, trust, information technology, and other factors on service quality and satisfaction should be studied. Second, except for an overall impression, we know little about the actual value of public service centers, thus, public service center performance evaluation and public value may be interesting issues to study. Third, in the wave of Comprehensively Deepening Reforms and promoting the modernization of national governance systems and governance capacity in China, the inter-departmental cooperation mechanism of public service centers should be studied. Finally, in order to provide smarter service, the value of related data should be mined out. Thus, the study of the integration, mining, and analysis of the service data will be a good topic.

\section{ACKNOWLEDGMENT}

This paper is supported by NSFC of China (Project No. 71734002 and 71373093) and the Fundamental Research Funds for the Central Universities(HUST:2015QT008). The authors wish to thank the anonymous reviewers for their constructive comments on the earlier version of the article and the editors of IJPADA. 


\section{REFERENCES}

Ai, Y. W., \& Yan, D. C. (2007). Achievements, Problems and Countermeasures in the Construction of Local Administrative Service Center. Chinese Public Administration, 1, 45-47.

Carlson, J., \& O'Cass, A. (2010). Exploring the Relationships Between E-Service Quality, Satisfaction, Attitudes and Behaviours in Content-Driven E-Service Web Sites. Journal of Services Marketing, 24(2), 112-127. doi:10.1108/08876041011031091

Chen, Y. H. (2015). Research on the coordinated development of administrative service center and e-government on an overall perspective. E-Government, (04), 49-55.

Delone, W. H., \& McLean, E. R. (2003). The DeLone and McLean Model of Information Systems Success: A TenYear Update. Journal of Management Information Systems, 19(4), 9-30. doi:10.1080/07421222.2003.11045748

Ding, Y. (2010). Quality in is Research: Theory and Validation of Constructs for Service, Information, and System(Doctoral dissertation). Atlanta: Georgia State University; Retrieved from http://scholarworks.gsu.edu/ cis_diss/42

Giese, J. L., \& Cote, J. A. (2000). Defining Consumer Satisfaction. Academy of Marketing Science Review, l(1).

Gu, P. A. (2015). Preface 2. In L. Ai \& G. Wang (Eds.), Remodeling Public-oriented Government Services. Beijing, China: Social Sciences Academic Press.

Guo, Z. P. (2016). Discussion About the Development and Direction of Government Service Center. Practice and Theory of Sezs., (3), 47-50.

Hsu, S. H. (2008). Developing an Index for Online Customer Satisfaction: Adaptation of American Customer Satisfaction Index. Expert Systems with Applications, 34(4), 3033-3042. doi:10.1016/j.eswa.2007.06.036

Hu, P. J., Brown, S. A., Thong, J. Y. L., Chan, F. K. Y., \& Tam, K. Y. (2009). Determinants of Service Quality and Continuance Intention of Online Services: The Case of eTax. Journal of the American Society for Information Science and Technology, 60(2), 292-306. doi:10.1002/asi.20956

Jiang, H. Y., \& Tao, H. Y. (2007). Administrative Service Center: Performance, Difficulties and Trends. Chinese Public Administration(03), 47-50.

Kang, Y. S., \& Lee, H. (2010). Understanding the Role of an IT Artifact in Online Service Continuance: an Extended Perspective of User Satisfaction. Computers in Human Behavior, 26(3), 353-364. doi:10.1016/j. chb.2009.11.006

Kao, T. D., \& Lin, W. T. (2016). The Relationship Between Perceived E-Service Quality and Brand Equity: A Simultaneous Equations System Approach. Computers in Human Behavior, 57, 208-218. doi:10.1016/j. chb.2015.12.006

Kettinger, W. J., \& Lee, C. C. (1994). Perceived Service Quality and User Satisfaction with the Information Services Function. Decision Sciences, 25(5-6), 737-766. doi:10.1111/j.1540-5915.1994.tb01868.x

Li, G. (2005, 2005-11-10). The Street of Foreign Trade and Economic Cooperation in Guangzhou Has Been 20 Years Old. 2016-01-24, from http://www.people.com.cn/GB/paper49/16132/1425574.html

Lin, K., Chen, N., \& Fang, K. (2011). Understanding E-Learning Continuance Intention: A Negative Critical Incidents Perspective. Behaviour \& Information Technology, 30(1), 77-89. doi:10.1080/01449291003752948

Liu, X. P., \& Zheng, L. (2015). Cross-Departmental Collaboration in One-Stop Service Center for Smart Governance in China: Factors,Strategies and Effectiveness. Government Information Quarterly. doi:10.1016/j. giq.2015.12.001

Mouakket, S. (2014). Investigating the Motives of Customers' Continuance Intentions towards Online Reservation: The Role of E-Service Quality. Journal of Organizational and End User Computing, 26(2), 18-40. doi:10.4018/ joeuc. 2014040102

Papadomichelaki, X., Magoutas, B., Halaris, C., Apostolou, D., \& Mentzas, G. (2006). A Review of Quality Dimensions in e-Government Services. In Proceedings of International Conference on Electronic Government. Berlin: Springer. doi:10.1007/11823100_12 
Parasuraman, A., Berry, L. L., \& Zeithaml, V. A. (1991). Refinement and Reassessment of the SERVQUAL Scale. Journal of Retailing, 67(4), 420-450.

Parasuraman, A., Zeithaml, V. A., \& Berry, L. L. (1988). SERVQUAL: A Multiple-Item Scale for Measuring Consumer Perceptions of Service Quality. Journal of Retailing, 64(1), 12-37.

Parasuraman, A., Zeithaml, V. A., \& Malhotra, A. (2005). E-S-QUAL:a Multiple-Item Scale for Assessing Electronic Service Quality. Journal of Service Research, 7(3), 213-233. doi:10.1177/1094670504271156

Pitt, L. F., Watson, R. T., \& Kavan, C. B. (1995). Service Quality:a Measure of Information Systems Effectiveness. Management Information Systems Quarterly, 19(2), 173-187. doi:10.2307/249687

Research Team of Chinese Society for Public Administration. (2012). A Report on Construction and Management of Government Service Center. Chinese Public Administration, (12), 7-11.

Ruan, Z. Z. (2006). A Study On Constructing Government Affairs Service Center [Master thesis]. Jilin University, Changchun. Retrieved from http://www.cnki.net/KCMS/detail/detailall.aspx?filename=2006115740. nh\&dbcode $=$ CMFD $\&$ dbname $=$ CMFD0506

Sá, F., Rocha, Á., \& Cota, M. P. (2016). Potential Dimensions for a Local e-Government Services Quality Model. Telematics and Informatics, 33(2), 270-276. doi:10.1016/j.tele.2015.08.005

Seddon, P., \& Kiew, M. (1996). A Partial Test and Development of DeLone and McLean's Model of is Success. Australasian Journal of Information Systems, 4(1), 90-109. doi:10.3127/ajis.v4i1.379

Stamenkov, G., \& Dika, Z. (2015). A Sustainable E-Service Quality Model. Journal of Service Theory and Practice, 25(4), 414-442. doi:10.1108/JSTP-09-2012-0103

Subramanian, N., Gunasekaran, A., Yu, J., Cheng, J., \& Ning, K. (2014). Customer Satisfaction and Competitiveness in the Chinese E-retailing: Structural Equation Modeling (SEM) Approach to Identify the Role of Quality Factors. Expert Systems with Applications, 41(1), 69-80. doi:10.1016/j.eswa.2013.07.012

Susniene, D. (2012). Quality Approach to the Sustainability of Public Transport. Transportation Science \& Technology, 27(1), 102-110.

Udo, G. J., Bagchi, K. K., \& Kirs, P. J. (2010). An Assessment of Customers' E-Service Quality Perception, Satisfaction and Intention. International Journal of Information Management, 30(6), 481-492. doi:10.1016/j. ijinfomgt.2010.03.005

Wang, W. T., Xie, Y. Q., \& Xie, X. (2014). Study on Evolution and Progress of D\&M Information System Success Model. Information Studies: Theory \& Application, 37(6), 73-76.

Wang, Y., \& Liao, Y. (2008). Assessing eGovernment Systems Success: A Validation of the DeLone and McLean Model of Information Systems Success. Government Information Quarterly, 25(4), 717-733. doi:10.1016/j. giq.2007.06.002

Wangpipatwong, S., Chutimaskul, W., \& Papasratorn, B. (2008). Understanding Citizen's Continuance Intention to Use e-Government Website: A Composite View of Technology Acceptance Model and Computer Self-Efficacy. The Electronic. Journal of E-Government, 6(1), 55-64.

Wangpipatwong, S., Chutimaskul, W., \& Papasratorn, B. (2010). Quality Enhancing the Continued Use of E-Government Web Sites: Evidence From E-Citizens of Thailand. In V. Weerakkody (Ed.), Applied Technology Integration in Governmental Organizations: New E-Government Research (pp. 20-36). Hershey, PA: IGI Global.

Website of ACSI. (2016). Retrieved 2016-01-24 from http://www.theacsi.org

Wong, K. K. (2013). Partial Least Squares Structural Equation Modeling (PLS-SEM) Techniques Using SmartPLS. Marketing Bulletin, 24(1).

Xu, Y. Y. (2007). Construction of Administrative Service Center with the Perspective of New Public Service Theory. Chinese Public Administration, (10), 15-18.

Yang, Y. F. (2013). Evaluation of E-Governance Service Quality: Research and Inspiration. Information and Documentation Services, (06), 69-74. 
Yeh, R. K., \& Teng, J. T. (2012). Extended conceptualisation of perceived usefulness: empirical test in the context of information system use continuance. Behaviour \& Information Technology, 31(5), 525-540. doi:10 $.1080 / 0144929 X .2010 .517272$

Yu, X. Q., Wu, B., \& Jiang, W. Q. (2016). Study On the Administration Service Center Performance Based On the Holistic Governance. Chinese Public Administration, (3), 54-59.

Zhang, L. (2009). The Study On Mobile Service Quality and Customer Satisfaction [Doctoral dissertation]. Wuhan: Huazhong University of Science and Technology. Retrieved from http://www.cnki.net/KCMS/detail/ detailall.asp $x$ ffilename $=2010042299$.nh $\&$ dbcode $=$ CDFD $\&$ dbname $=$ CDFD0911

Zhang, R. X., \& Qin, H. (2010). Administrative Service Center: Vision, Path Selection and Approach Strategy. Jilin University Journal Social Sciences Edition, (05), 43-49.

Zheng, S. M., Zheng, C., \& Liu, Z. M. (2012). Research on the Online Joint Approval with the Perspective of Joined- Up Government. Chinese Public Administration, (09), 23-26.

Zhuo, Y., \& Chen, C. (2015). Innovation Diffusion of Public Service \& Standardization Based on the Gradient Theory. Journal of Xiamen University (Arts \& Social Sciences), (02), 29-39. 


\section{APPENDIX}

Table 6. Likert Response Format (LRF) Questionnaire (originally distributed in Chinese)

\begin{tabular}{|c|c|}
\hline Latent variables and measures variables & T-statistic \\
\hline \multicolumn{2}{|l|}{ Information quality(INFQ) } \\
\hline INFQ1. The service center offers precise information. & 41.748 \\
\hline INFQ2. The service center offers sufficient information. & 63.687 \\
\hline INFQ3. The service center offers up to date information. & 43.536 \\
\hline INFQ4. The service center offers information of a high quality. & 45.464 \\
\hline \multicolumn{2}{|l|}{ System quality(SYSQ) } \\
\hline SYSQ1. The equipment and system interfaces in the service center are user-friendly. & 53.599 \\
\hline SYSQ2. The equipment and systems in the service center are very easy to use. & 63.005 \\
\hline SYSQ3. Overall, the whole system in the service center is of a very high quality. & 57.847 \\
\hline \multicolumn{2}{|l|}{ Service quality(SERQ) } \\
\hline SERQ1. Staff members show willingness to help me solve my problems. & 46.154 \\
\hline SERQ2. I feel safe and sound in handling my affairs in the service center. & 56.419 \\
\hline SERQ3. The staff members show great interest in my situation. & 27.121 \\
\hline \multicolumn{2}{|l|}{ Specific satisfaction(SPES) } \\
\hline SPES1. The last time, I was very satisfied with the service center. & 53.707 \\
\hline SPES2. The last time, the result went beyond my expectation. & 50.186 \\
\hline SPES3. The last time, I had a very good experience. & 49.893 \\
\hline \multicolumn{2}{|l|}{ Accumulative satisfaction(ACCS) } \\
\hline ACCS1. My experiences in the service center are always very good. & 50.921 \\
\hline ACCS2. The service center always meets my expectations. & 83.111 \\
\hline ACCS3. Overall, I am always satisfied with the service center. & 51.036 \\
\hline \multicolumn{2}{|l|}{ Continuous motivation(CONM) } \\
\hline CONM1. I would visit the service center if I had similar needs in the future. & 95.876 \\
\hline CONM2. If I could choose, I would go to nowhere else but to the service center. & 98.779 \\
\hline
\end{tabular}

Chenghan Ming is a doctoral candidate at College of Public Administration (CPA), Huazhong University of Science and Technology (HUST). He has lived through the bachelor and master's life in CPA, HUST. And now he majors in Electronic Government. His main research interests include E-government, E-services, public participation, and innovation management.

Tao Chen is a professor at College of Public Administration, Huazhong University of Science and Technology, China. He holds a master and doctoral degree in Management Information Systems from HUST. His research has been funded by National Science Foundation of China. He has published papers in journals like International Journal of Project Management, Information Systems Journal, Journal of Global Information Management and Expert Systems with Applications. His main research interests include E-government, E-services quality, smart city and medical information systems.

Qi Ai is a Lecturer in Strategic Management at Faculty of Business and Law, the University of Northampton, UK. He is also a research fellow at the College of Public Administration, Huazhong University of Science and Technology, China. His research interests include mergers and acquisitions, the internationalisation of Chinese multinational corporations (MNCs), and knowledge transfer in emerging MNCs. His work appears in journals such as Asia Pacific Journal of Management, Journal of Organizational Change Management, Advances in Mergers and Acquisitions. 